\title{
Assessment of Trace Elements in Tissues of Fish Species: Multivariate Study and Safety Evaluation
}

\author{
Edevaldo Silva, ${ }^{a, b, c}$ Fernanda N. Costa, ${ }^{a, b}$ Thais L. Souza, ${ }^{a, b}$ Zenira C. V. Viana, ${ }^{d}$ \\ Anderson S. Souza, ${ }^{e}$ Maria G. A. Korn ${ }^{*, a, b}$ and Sergio L. C. Ferreira ${ }^{a, b}$ \\ ${ }^{a}$ Instituto de Química, Universidade Federal da Bahia, Campus de Ondina, \\ 40170-115 Salvador-BA, Brazil \\ ${ }^{b}$ Instituto Nacional de Ciência e Tecnologia (INCT) de Energia e Ambiente, \\ Universidade Federal da Bahia, 40170-290 Salvador-BA, Brazil \\ 'Unidade Acadêmica de Ciências Biológicas, Universidade Federal de Campina Grande, \\ CP 64, 58700-970 Patos-PB, Brazil \\ ${ }^{d}$ Instituto de Ciências da Saúde, Universidade Federal da Bahia, Vale do Canela, \\ 40110-100 Salvador-BA, Brazil \\ eInstituto Multidisciplinar em Saúde, Universidade Federal da Bahia, Rua Rio de Contas, 58, \\ Bairro Candeias, 45029-064 Vitória da Conquista-BA, Brazil
}

\begin{abstract}
Levels of As, $\mathrm{Cd}, \mathrm{Cr}, \mathrm{Cu}, \mathrm{Li}, \mathrm{Mn}, \mathrm{Mo}, \mathrm{Ni}, \mathrm{Pb}, \mathrm{Sb}$ and $\mathrm{Se}$ in muscle, gill, stomach, liver, kidney and gonad tissues of six different fish species (Caranx latus, Bagre marinus, Archosargus rhomboidalis, Lutjanus synagris, Scomberomorus cavalla and Sphyraena guachancho) from the Todos os Santos Bay (Bahia State, Brazil) were evaluated. The elements were determined by inductively coupled plasma mass spectrometry (ICP-MS) after wet digestion using reflux system with a cold finger. The detected concentration ranges were as follows ( $\mathrm{mg} \mathrm{kg}^{-1}$ dry weight): $<0.49-27.31$ for As, $<0.013-1.12$ for $\mathrm{Cd}, 0.38-6.05$ for $\mathrm{Cr}, 0.17-28.12$ for $\mathrm{Cu},<0.092-1.19$ for $\mathrm{Li}$, 0.16-55.9 for $\mathrm{Mn},<0.034-1.24$ for $\mathrm{Mo},<0.067-15.57$ for $\mathrm{Ni},<0.013-0.60$ for $\mathrm{Pb},<0.144$ for $\mathrm{Sb}$ and 0.57-14.6 for Se. Highest concentrations of trace elements were observed in kidney, liver and gill tissues.
\end{abstract}

Keywords: ICP-MS, PCA, food analysis, food safety, Todos os Santos Bay

\section{Introduction}

Fish consumption is an important dietary source of high-quality proteins, minerals, trace elements and essential fatty acids, including omega-3 acids. So, fish is an important source of food and essential nutrients to population of some regions, being part of the cultural traditions of many people. ${ }^{1}$ However, fish and seafood may pose risks to human health because they may contain toxic substances, such as trace elements and persistent organic pollutants. ${ }^{2}$

Fish serves as advantageous bioindicators because (i) they have long lifespans; (ii) they develop and live in water allowing continuous monitoring of pollutants and simultaneous spatial integration of pollutant data; and (iii) they are relatively easy to sample.

\footnotetext{
*e-mail: korn@ufba.br
}

Therefore, many studies have been conducted on the accumulation of trace elements in fish and other organisms in aqueous environments. ${ }^{3}$ Fish incorporates trace elements by ingestion of suspended particulate matter in the water column and of food, by ion exchange of dissolved elements across lipophilic membranes (e.g., the gills) and by adsorption of elements on tissue and membrane surfaces. Since that the element distribution in different tissues depends on the way of exposure, i.e., dietary and/or aqueous exposure, the measurement of this distribution can serve as a pollution indicator. ${ }^{4}$ The majority of trace element contamination studies using fish have focused on accumulation in soft tissues, such as liver, kidney, gill and/or muscle. Muscle is commonly analyzed to determine contaminant concentrations and to assess health risks because it is the main fish tissue consumed by humans. ${ }^{2-6}$ However, organs, actively involved 
in metabolism, including gill, liver and kidney tissues, are known to accumulate greater amounts of trace elements than muscle..$^{7-10}$

The pattern of trace elements distribution is usually evaluated using univariate procedures, but the use of multivariate pattern recognition techniques such as principal component analysis (PCA) and hierarchical cluster analysis (HCA) can provide further interpretation of results. PCA and HCA are multivariate analysis techniques commonly employed in the evaluation of food data allowing the establishment of similarities and differences in a data set. ${ }^{11-21}$

In this study, the contents of eleven trace elements (As, Cd, Cr, Cu, Li, Mn, Mo, Ni, Pb, Sb and Se) were determined in muscle, gills, stomach, liver, kidney and gonads of six selected fish species from Todos os Santos Bay, Bahia State, Brazil. The employed analytical technique was the inductively coupled plasma mass spectrometry (ICP-MS) and the investigated fish species were Caranx latus ("guarajuba"), Bagre marinus ("bagre"), Archosargus rhomboidalis ("sambuio"), Lutjanus synagris ("ariacó"), Scomberomorus cavalla ("cavala") and Sphyraena guachancho ("bicuda"). These species were selected based on their relevance to the commercial fishing in the Bahia State and to the fish consumption by the local population. Accumulation patterns relating organs and elements were evaluated using PCA and HCA to establish classification, and also to identify the key discriminants that distinguish the samples.

\section{Experimental}

\section{Sample collection}

Six different fish species (a total of 31 samples, fish species mentioned above) were collected from three suppliers of fresh fish in Salvador city (Bahia State, Brazil) during two subsequent summers (December 2010-January 2011, namely first period (S1), and December 2011-January 2012, namely second period (S2)) to minimize seasonal environmental variations as much as possible. Immediately after collection, the fish samples were stored on ice in an insulated box and promptly transferred to the laboratory.

\section{Instrumentation}

A quadrupole ICP-MS Xseries II (Thermo, Germany) equipped with a hexapole collision cell (CC) was used to determine the eleven trace element content in the samples. Internal standards (Ge, Rh, Tl, In, Bi and Sc) were added to compensate for any effects from acid treatment or instrumental drift.
The instrument software control allowed rapid switching between standard mode (no gas, cell vented to mass analyzer chamber) and CC mode, while continuously aspirating the sample. A premixed gas mixture containing $\mathrm{H}_{2}(7 \%)$ in $\mathrm{He}\left(\mathrm{H}_{2} \mathrm{O}\right.$ and other impurities at $\left.5 \mathrm{ppm}\right)$ was admitted into $\mathrm{CC}$ under flow control through stainless steel lines. The measurements were made using a nickel sampler, skimmer cones (1.0 and $0.7 \mathrm{~mm}$ diameter orifices) and a standard concentric nebulizer. A glass impact bead spray chamber (cooled to $4{ }^{\circ} \mathrm{C}$ by a Peltier cooler) and a shielded Fassel torch were used to minimize the plasma potential and thereby to obtain a low and narrow initial ion energy distribution.

Optimal values for instrumental parameters were: radio frequency applied power of $1.3 \mathrm{~kW}$, plasma gas flow rate of $13 \mathrm{~L} \mathrm{~min}^{-1}$, auxiliary gas flow rate of $0.7 \mathrm{~L} \mathrm{~min}^{-1}$, nebulizer gas flow rate of $0.87 \mathrm{~L} \mathrm{~min}^{-1}$, scanning mode (peak jump), residence time of $10 \mathrm{~ms}$, number of readings per replicate equal to 3 , conditions $\left({ }^{140} \mathrm{Ce}^{16} \mathrm{O}^{+} /{ }^{140} \mathrm{Ce}\right.$ and ${ }^{137} \mathrm{Ba}^{++} /{ }^{137} \mathrm{Ba}^{+}<2 \%$ ) and $\mathrm{CC}$ mode gas flow equal to $6.5 \mathrm{~L} \mathrm{~min}^{-1}$. The isotopes measured in this study were ${ }^{7} \mathrm{Li},{ }^{53} \mathrm{Cr},{ }^{55} \mathrm{Mn},{ }^{60} \mathrm{Ni},{ }^{65} \mathrm{Cu},{ }^{75} \mathrm{As},{ }^{82} \mathrm{Se},{ }^{95} \mathrm{Mo},{ }^{111} \mathrm{Cd},{ }^{121} \mathrm{Sb}$ and ${ }^{208} \mathrm{~Pb}$. The external calibration was accomplished with aqueous solutions in the concentrations of $0.1,0.5,1.0$, 1.5, 2.0, 4.0, 6.0, 8.0 and $10.0 \mu \mathrm{g} \mathrm{L}^{-1}$ in $1 \%(\mathrm{v} / \mathrm{v})$ nitric acid. Internal standards (Tl, In, Bi, Ge, Rh and Sc) were added to compensate for any acid effects and instrument drift.

\section{Reagents and solutions}

All material, glassware and utensils were washed with water and distilled water. Then, they were all placed in a dilute solution of detergent ( $0.5 \%$ Extran) for $24 \mathrm{~h}$, and after three washes with distilled water, were immersed in $10 \%$ $\mathrm{HNO}_{3}$ for an additional $24 \mathrm{~h}$. All of these materials were then washed twice with distilled water, once with ultrapure water and then stored until analysis.

All solvents and reagents were of the highest commercially available purity grade. Deionized water (resistivity $18 \mathrm{M} \Omega \mathrm{cm}$ ) obtained from a Milli-Q Pluswater purification system (Millipore, Molsheim, France) was used to prepare all standard and sample solutions. Distilled nitric acid and $30 \%(\mathrm{~m} / \mathrm{m}) \mathrm{H}_{2} \mathrm{O}_{2}$ (Merck, Darmstadt, Germany) were used for sample digestion.

Monoelemental stock solutions (1 $\mathrm{g} \mathrm{L}^{-1}$, high-purity grade) of $\mathrm{As}, \mathrm{Cd}, \mathrm{Cr}, \mathrm{Cu}, \mathrm{Li}, \mathrm{Mn}, \mathrm{Mo}, \mathrm{Ni}, \mathrm{Pb}, \mathrm{Sb}$ and $\mathrm{Se}$ and a multi-element solution (100 $\left.\mathrm{mg} \mathrm{L}^{-1}\right)$ of $\mathrm{Bi}, \mathrm{Ge}, \mathrm{In}$, $\mathrm{Tl}$, Rh and Sc were purchased from Merck (Darmstadt, Germany). The purity of the plasma torch argon was greater than $99.99 \%$. 


\section{Sample preparation and digestion procedure}

Following morphometric measurements of the total length and width of each fish, they were filleted, and the muscle tissue was separated from the organs on the same day of the collection to avoid sample degradation.

To analyze tissue-specific concentrations of trace elements, fish samples were dissected, and muscle, gills, stomach, liver, kidney and gonads were carefully separated from other tissues. After dissection, the tissue samples were homogenized, lyophilized, homogenized (particles $\leq 149 \mathrm{~mol} \mathrm{~L}^{-1}, 100 \mu \mathrm{m}$ mesh) and stored in labeled glass bottles. The lyophilization process was carried out with a vacuum pressure of $10 \mathrm{mmHg}$ for ca. $36 \mathrm{~h}$ in a freezer at $-40{ }^{\circ} \mathrm{C}$. The humidity in the tissues was determined by wet and dry mass difference after lyophilization.

Digestion was carried out in a temperature-regulated block digester. Approximately $100 \mathrm{mg}$ of sample were digested with $6 \mathrm{~mL}$ of $14.1 \mathrm{~mol} \mathrm{~L}^{-1} \mathrm{HNO}_{3}$ and $3 \mathrm{~mL}$ of $\mathrm{H}_{2} \mathrm{O}_{2}$ in a block digester for $2 \mathrm{~h}$ at $180 \pm 10^{\circ} \mathrm{C}$, using cold finger to prevent loss of volatile analytes and excessive evaporation of the acids during the heating. ${ }^{22}$ After cooling to ambient temperature, the solution was transferred to $35 \mathrm{~mL}$ capacity flasks, and the volume was adjusted with ultrapure water. All samples were analyzed in triplicate.

\section{Validation studies}

For every batch of digested samples, three blanks were prepared, and the accuracies of the employed methods were assessed using certified reference materials: CRM 1566b Oyster Tissue (National Institute of Standards and Technology) and DOLT-4 Dogfish Liver (National Research Council of Canada). The experimental results were in good agreement with the certified values.

The values obtained (in $\mathrm{mg} \mathrm{kg}^{-1}$ dry weight) from the analysis of four replicates of these samples were as follows: (i) for CRM 1566b Oyster Tissue: Cd (certified 2.48 \pm 0.08 ; found $93 \%: 2.37 \pm 0.1$ ), $\mathrm{Pb}$ (certified $0.308 \pm 0.009$; found 103\%: $0.317 \pm 0.02), \mathrm{Ni}$ (certified $1.04 \pm 0.09$; found $103 \%: 1.07 \pm 0.03$ ), Se (certified $1.80 \pm 0.15$; found $98 \%$ : $1.77 \pm 0.2), \mathrm{Mn}$ (certified $18.5 \pm 0.2 ;$ found $91 \%: 16.7 \pm 0.9)$ and $\mathrm{Cu}$ (certified $71.6 \pm 1.6$; found 101\%: $67.45 \pm 0.75$ ); (ii) for DOLT-4 Dogfish Liver: Cd (certified $24.3 \pm 0.8$; found $94 \%: 23.8 \pm 0.3$ ), $\mathrm{Pb}$ (certified $0.16 \pm 0.04$; found 90\%: $0.14 \pm 0.02), \mathrm{Ni}$ (certified $0.97 \pm 0.11$; found 93\%: $0.90 \pm 0.09$ ), Se (certified $8.3 \pm 1.34$; found $91 \%$ : $7.53 \pm 0.46)$ and $\mathrm{Cu}$ (certified $31.2 \pm 1.1$; found $94 \%$ : $28.7 \pm 0.2)$.

The limits of detection (LOD) and of quantification (LOQ) of each analyte were calculated as the analyte concentration that corresponded to three and ten times, respectively, the standard deviation of ten independent measurements of the blank, divided by the slope of the calibration curve, multiplied by the dilution factor and divided by the sample mass used for sample preparation. The LOQ values obtained for the experimental method were as follows (in $\mathrm{mg} \mathrm{kg}^{-1}$ ): ${ }^{7} \mathrm{Li}=0.092,{ }^{53} \mathrm{Cr}=0.071,{ }^{55} \mathrm{Mn}=0.021$, ${ }^{60} \mathrm{Ni}=0.067,{ }^{65} \mathrm{Cu}=0.095,{ }^{95} \mathrm{Mo}=0.034,{ }^{111} \mathrm{Cd}=0.013$, ${ }^{208} \mathrm{~Pb}=0.042$ and ${ }^{121} \mathrm{Sb}=0.144,{ }^{75} \mathrm{As}=0.102$ and ${ }^{82} \mathrm{Se}=0.037$.

\section{Statistical analysis}

Experimental data were evaluated by multivariate statistical techniques: PCA and HCA, using the computer software package 6.0 Statistica (Statsoft).

The chemical descriptors were the contents of each mineral element in the organs. The pattern recognition methods (PCA and HCA) were applied to the data matrix composed of 08 columns (concentrations of the elements) and 396 rows (organ samples) in order to differentiate between groups de organs. The elements $\mathrm{Cd}, \mathrm{Pb}$ and $\mathrm{Sb}$ were not included in this analysis because they presented values below LOQ in most samples. The software package 6.0 Statistica was used for all the chemometric calculations. The data were auto-scaled prior to application of PCA and HCA.

Relationships between the concentrations of trace element in different tissues and between the concentrations of different trace elements within the same tissue were assessed by the Spearman's non-parametric correlation test. $^{23}$

\section{Results and Discussion}

\section{Trace elements concentrations in tissues}

The mean length and weight of all six fish species ranged from $25.7 \pm 2.1$ to $48.7 \pm 0.6 \mathrm{~cm}$ and $268 \pm 22$ to $793 \pm 32 \mathrm{~g}$, respectively. The average percentage of humidity of the tissues was $77.4 \pm 1.2 \%$. Trace element concentrations in muscle, gill, stomach, liver, kidney and gonad tissues for the two sampling periods are shown in Tables 1 and 2 .

The concentrations of different trace elements varied with species and the type of tissue analyzed. The concentrations of $\mathrm{Li}, \mathrm{Mo}$ and $\mathrm{Ni}$ in muscle were below LOQ in all analyzed samples.

Manganese was detected in all of the examined fish samples, and its concentration, dependent on species and tissue type, varied from $0.11-1.37 \mathrm{mg} \mathrm{kg}^{-1}$ in muscle, 
Table 1. Concentrations of trace elements in fish tissues from the Todos os Santos Bay, Bahia, Brazil (period S1: Dec/2010-Jan/2011)

\begin{tabular}{|c|c|c|c|c|c|c|}
\hline \multirow{2}{*}{ Element } & \multirow{2}{*}{ Tissue } & \multicolumn{5}{|c|}{ Concentration of elements in species / ( $\mathrm{mg} \mathrm{kg}^{-1}$ dry weight), $\mathrm{n}=3$} \\
\hline & & C. latus & B. marinus & A. rhomboidalis & L. synagris & S. cavalla \\
\hline \multirow{6}{*}{ As } & muscle & $4.26 \pm 0.19^{\mathrm{bB}}$ & $4.21 \pm 0.16^{\mathrm{bC}}$ & $2.55 \pm 0.17^{\mathrm{cD}}$ & $4.78 \pm 0.10^{\mathrm{aC}}$ & $2.08 \pm 0.05^{\mathrm{dD}}$ \\
\hline & gills & $3.07 \pm 0.08^{\mathrm{aD}}$ & $0.49 \pm 0.05^{\mathrm{dE}}$ & $2.41 \pm 0.15^{\mathrm{cD}}$ & $2.77 \pm 0.14^{\mathrm{bD}}$ & $0.59 \pm 0.05^{\mathrm{dE}}$ \\
\hline & stomach & $4.48 \pm 0.08^{\mathrm{aB}}$ & $1.14 \pm 0.11^{\mathrm{bD}}$ & $1.28 \pm 0.13^{\mathrm{bE}}$ & $1.38 \pm 0.04^{\mathrm{bE}}$ & $4.75 \pm 0.19^{\mathrm{aB}}$ \\
\hline & liver & $5.00 \pm 0.14^{\mathrm{dA}}$ & $6.28 \pm 0.09^{\mathrm{bA}}$ & $8.57 \pm 0.52^{\mathrm{aA}}$ & $6.02 \pm 0.17^{\mathrm{bcA}}$ & $5.28 \pm 0.49^{\mathrm{cdAB}}$ \\
\hline & kidney & $3.78 \pm 0.11^{\mathrm{dC}}$ & $5.33 \pm 0.01^{\mathrm{bB}}$ & $7.41 \pm 0.26^{\mathrm{aB}}$ & $4.73 \pm 0.02^{\mathrm{cC}}$ & $5.71 \pm 0.38^{\mathrm{bA}}$ \\
\hline & gonad & $4.87 \pm 0.11^{\mathrm{bA}}$ & $5.26 \pm 0.07^{\mathrm{aB}}$ & $3.55 \pm 0.11^{\mathrm{cC}}$ & $5.26 \pm 0.12^{\mathrm{aB}}$ & $3.54 \pm 0.13^{\mathrm{cC}}$ \\
\hline \multirow{6}{*}{$\mathrm{Cd}$} & muscle & $<\mathrm{LOQ}$ & $<$ LOQ & $<\mathrm{LOQ}$ & $<\mathrm{LOQ}$ & $<\mathrm{LOQ}$ \\
\hline & gills & $0.093 \pm 0.004^{\mathrm{bC}}$ & $<\mathrm{LOQ}$ & $0.525 \pm 0.033^{\mathrm{aA}}$ & $<\mathrm{LOQ}$ & $<\mathrm{LOQ}$ \\
\hline & stomach & $1.37 \pm 0.02^{\mathrm{aA}}$ & $<\mathrm{LOQ}$ & $0.423 \pm 0.024^{\mathrm{bB}}$ & $<\mathrm{LOQ}$ & $<\mathrm{LOQ}$ \\
\hline & liver & $0.822 \pm 0.004^{\mathrm{aB}}$ & $<\mathrm{LOQ}$ & $0.401 \pm 0.010^{\mathrm{cB}}$ & $<\mathrm{LOQ}$ & $0.533 \pm 0.016^{\mathrm{dA}}$ \\
\hline & kidney & $0.056 \pm 0.004^{\mathrm{bD}}$ & $<$ LOQ & $0.081 \pm 0.006^{\mathrm{aC}}$ & $<\mathrm{LOQ}$ & $0.060 \pm 0.001^{\mathrm{bB}}$ \\
\hline & gonad & $<\mathrm{LOQ}$ & $<\mathrm{LOQ}$ & $<\mathrm{LOQ}$ & $<\mathrm{LOQ}$ & $<\mathrm{LOQ}$ \\
\hline \multirow{6}{*}{$\mathrm{Cr}$} & muscle & $0.44 \pm 0.03^{\mathrm{cF}}$ & $0.42 \pm 0.00^{\mathrm{cE}}$ & $0.38 \pm 0.01^{\mathrm{cF}}$ & $1.30 \pm 0.08^{\mathrm{ac}}$ & $0.61 \pm 0.02^{\mathrm{bB}}$ \\
\hline & gills & $1.86 \pm 0.01^{\mathrm{aD}}$ & $1.73 \pm 0.04^{\mathrm{bC}}$ & $1.45 \pm 0.02^{\mathrm{cC}}$ & $1.04 \pm 0.03^{\mathrm{dCD}}$ & $0.74 \pm 0.01^{\mathrm{eB}}$ \\
\hline & stomach & $2.30 \pm 0.02^{\mathrm{aC}}$ & $2.26 \pm 0.05^{\mathrm{aB}}$ & $1.27 \pm 0.03^{\mathrm{bD}}$ & $1.16 \pm 0.05^{\mathrm{bCD}}$ & $1.27 \pm 0.02^{\mathrm{b}}$ \\
\hline & liver & $2.65 \pm 0.05^{\mathrm{cB}}$ & $4.37 \pm 0.08^{\mathrm{bA}}$ & $4.70 \pm 0.07^{\mathrm{cB}}$ & $2.73 \pm 0.04^{\mathrm{cB}}$ & $5.46 \pm 0.10^{\mathrm{aA}}$ \\
\hline & kidney & $2.94 \pm 0.06^{\mathrm{dA}}$ & $4.30 \pm 0.09^{\mathrm{cA}}$ & $5.41 \pm 0.16^{\mathrm{bA}}$ & $3.12 \pm 0.04^{\mathrm{dA}}$ & $6.05 \pm 0.06^{\mathrm{aA}}$ \\
\hline & gonad & $0.87 \pm 0.01^{\mathrm{aE}}$ & $0.78 \pm 0.02^{\mathrm{bD}}$ & $0.67 \pm 0.01^{\mathrm{dE}}$ & $0.67 \pm 0.02^{\mathrm{dD}}$ & $0.71 \pm 0.01^{\mathrm{cB}}$ \\
\hline \multirow{6}{*}{$\mathrm{Cu}$} & muscle & $1.11 \pm 0.04^{\mathrm{aF}}$ & $0.33 \pm 0.01^{\mathrm{dF}}$ & $0.80 \pm 0.09^{\mathrm{bF}}$ & $0.43 \pm 0.01^{\mathrm{cE}}$ & $0.17 \pm 0.01^{\mathrm{eF}}$ \\
\hline & gills & $2.38 \pm 0.06^{\mathrm{cD}}$ & $1.84 \pm 0.01^{\mathrm{dD}}$ & $1.69 \pm 0.12^{\mathrm{dD}}$ & $4.14 \pm 0.06^{6 \mathrm{C}}$ & $6.14 \pm 0.06^{\mathrm{bC}}$ \\
\hline & stomach & $3.91 \pm 0.02^{\mathrm{cB}}$ & $3.11 \pm 0.01^{\mathrm{dB}}$ & $3.84 \pm 0.15^{\mathrm{cB}}$ & $7.12 \pm 0.09^{\mathrm{bB}}$ & $7.62 \pm 0.20^{\mathrm{aB}}$ \\
\hline & liver & $5.19 \pm 0.06^{\mathrm{cA}}$ & $4.87 \pm 0.03^{\mathrm{cA}}$ & $5.28 \pm 0.12^{\mathrm{cA}}$ & $11.10 \pm 0.29^{\mathrm{bA}}$ & $15.14 \pm 0.66^{\mathrm{aA}}$ \\
\hline & kidney & $3.63 \pm 0.05^{\mathrm{bC}}$ & $2.87 \pm 0.01^{\mathrm{dC}}$ & $2.64 \pm 0.01^{\mathrm{eC}}$ & $4.42 \pm 0.10^{\mathrm{aC}}$ & $3.17 \pm 0.06^{\mathrm{cC}}$ \\
\hline & gonad & $1.67 \pm 0.02^{\mathrm{cE}}$ & $2.12 \pm 0.02^{\mathrm{bE}}$ & $2.21 \pm 0.17^{\mathrm{bE}}$ & $2.61 \pm 0.16^{\mathrm{aD}}$ & $2.25 \pm 0.05^{\mathrm{bE}}$ \\
\hline \multirow{6}{*}{$\mathrm{Li}$} & muscle & $<$ LOQ & $<$ LOQ & $<$ LOQ & $<$ LOQ & $<$ LOQ \\
\hline & gills & $0.815 \pm 0.015^{\mathrm{bA}}$ & $0.580 \pm 0.010^{\mathrm{dA}}$ & $0.100 \pm 0.080^{\mathrm{eC}}$ & $0.898 \pm 0.008^{\mathrm{aB}}$ & $0.750 \pm 0.009^{\mathrm{CB}}$ \\
\hline & stomach & $0.610 \pm 0.009^{\mathrm{dB}}$ & $0.170 \pm 0.010^{\mathrm{dB}}$ & $1.34 \pm 0.01^{\mathrm{aA}}$ & $1.06 \pm 0.04^{\mathrm{cA}}$ & $1.19 \pm 0.035^{\mathrm{bA}}$ \\
\hline & liver & $0.168 \pm 0.008^{\mathrm{bC}}$ & $0.143 \pm 0.003^{\mathrm{cc}}$ & $0.140 \pm 0.006^{\mathrm{cB}}$ & $0.220 \pm 0.010^{\mathrm{aC}}$ & $0.135 \pm 0.005^{\mathrm{cC}}$ \\
\hline & kidney & $<\mathrm{LOQ}$ & $<\mathrm{LOQ}$ & $<\mathrm{LOQ}$ & $<\mathrm{LOQ}$ & $<\mathrm{LOQ}$ \\
\hline & gonad & $<\mathrm{LOQ}$ & $<\mathrm{LOQ}$ & $<\mathrm{LOQ}$ & $<\mathrm{LOQ}$ & $<\mathrm{LOQ}$ \\
\hline \multirow{6}{*}{$\mathrm{Mn}$} & muscle & $0.77 \pm 0.06^{\mathrm{cD}}$ & $0.98 \pm 0.01^{\mathrm{bD}}$ & $1.37 \pm 0.06^{\mathrm{aD}}$ & $0.164 \pm 0.004^{\mathrm{eF}}$ & $0.450 \pm 0.018^{\mathrm{dE}}$ \\
\hline & gills & $13.4 \pm 0.2^{\mathrm{aA}}$ & $10.7 \pm 0.6^{\mathrm{bA}}$ & $3.36 \pm 0.07^{\mathrm{dCD}}$ & $11.0 \pm 0.9^{\mathrm{bC}}$ & $4.77 \pm 0.05^{\mathrm{cC}}$ \\
\hline & stomach & $1.46 \pm 0.02^{\mathrm{eC}}$ & $3.98 \pm 0.06^{\mathrm{dB}}$ & $55.9 \pm 2.9^{\mathrm{aA}}$ & $43.5 \pm 0.4^{\mathrm{bA}}$ & $30.9 \pm 0.6^{\mathrm{cA}}$ \\
\hline & liver & $3.00 \pm 0.02^{\mathrm{dB}}$ & $3.43 \pm 0.03^{\mathrm{dC}}$ & $16.5 \pm 0.2^{\mathrm{aB}}$ & $15.4 \pm 0.2^{\mathrm{bB}}$ & $8.11 \pm 0.26^{\mathrm{cB}}$ \\
\hline & kidney & $2.23 \pm 0.01^{\mathrm{c}}$ & $3.01 \pm 0.01^{\mathrm{bC}}$ & $5.25 \pm 0.09^{\mathrm{aC}}$ & $2.34 \pm 0.02^{\mathrm{cD}}$ & $2.80 \pm 0.16^{\mathrm{bD}}$ \\
\hline & gonad & $1.33 \pm 0.01^{\mathrm{cC}}$ & $1.45 \pm 0.02^{\mathrm{cD}}$ & $3.83 \pm 0.13^{\mathrm{aCD}}$ & $1.09 \pm 0.02^{\mathrm{dE}}$ & $2.24 \pm 0.07^{\mathrm{bD}}$ \\
\hline \multirow{6}{*}{ Mo } & muscle & $<$ LOQ & $<$ LOQ & $<\mathrm{LOQ}$ & $<$ LOQ & $<$ LOQ \\
\hline & gills & $0.074 \pm 0.003^{\mathrm{aD}}$ & $0.038 \pm 0.002^{\mathrm{cC}}$ & $0.061 \pm 0.001^{\mathrm{bD}}$ & $0.037 \pm 0.002^{\mathrm{cD}}$ & $0.048 \pm 0.002^{\mathrm{dD}}$ \\
\hline & stomach & $0.261 \pm 0.014^{\mathrm{ac}}$ & $0.038 \pm 0.001^{\mathrm{eC}}$ & $0.071 \pm 0.005^{\mathrm{dC}}$ & $0.083 \pm 0.001^{\mathrm{cC}}$ & $0.167 \pm 0.002^{\mathrm{bC}}$ \\
\hline & liver & $0.680 \pm 0.009^{\mathrm{dB}}$ & $0.236 \pm 0.003^{\mathrm{eB}}$ & $0.943 \pm 0.004^{\mathrm{bB}}$ & $0.750 \pm 0.010^{\mathrm{cA}}$ & $1.17 \pm 0.03^{\mathrm{aA}}$ \\
\hline & kidney & $1.07 \pm 0.05^{\mathrm{bA}}$ & $0.416 \pm 0.008^{\mathrm{eA}}$ & $1.29 \pm 0.0^{\mathrm{aA}}$ & $0.653 \pm 0.006^{\mathrm{cB}}$ & $0.582 \pm 0.014^{\mathrm{dB}}$ \\
\hline & gonad & $<\mathrm{LOQ}$ & $<\mathrm{LOQ}$ & $<\mathrm{LOQ}$ & $<\mathrm{LOQ}$ & $<\mathrm{LOQ}$ \\
\hline
\end{tabular}


Table 1. Concentrations of trace elements in fish tissues from the Todos os Santos Bay, Bahia, Brazil (period S1: Dec/2010-Jan/2011) (cont.)

\begin{tabular}{|c|c|c|c|c|c|c|}
\hline \multirow{6}{*}{$\mathrm{Ni}$} & muscle & $<\mathrm{LOQ}$ & $<\mathrm{LOQ}$ & $<\mathrm{LOQ}$ & $<\mathrm{LOQ}$ & $<\mathrm{LOQ}$ \\
\hline & gills & $4.76 \pm 0.11^{\mathrm{aC}}$ & $3.51 \pm 0.07^{\mathrm{bB}}$ & $1.33 \pm 0.03^{\mathrm{dD}}$ & $2.12 \pm 0.21^{\mathrm{cB}}$ & $1.23 \pm 0.06^{\mathrm{eC}}$ \\
\hline & stomach & $3.76 \pm 0.11^{\mathrm{aD}}$ & $1.91 \pm 0.05^{\mathrm{cD}}$ & $2.32 \pm 0.11^{\mathrm{bC}}$ & $0.88 \pm 0.01^{\mathrm{eD}}$ & $1.07 \pm 0.05^{\mathrm{dD}}$ \\
\hline & liver & $5.88 \pm 0.10^{\mathrm{aB}}$ & $2.66 \pm 0.03^{\mathrm{cC}}$ & $5.17 \pm 0.23^{\mathrm{bB}}$ & $1.90 \pm 0.07^{\mathrm{eC}}$ & $2.52 \pm 0.03^{\mathrm{dB}}$ \\
\hline & kidney & $9.11 \pm 0.10^{\mathrm{aA}}$ & $6.33 \pm 0.14^{\mathrm{cA}}$ & $8.46 \pm 0.17^{\mathrm{bA}}$ & $5.86 \pm 0.09^{\mathrm{dA}}$ & $4.08 \pm 0.05^{\mathrm{eA}}$ \\
\hline & gonad & $0.21 \pm 0.01^{\mathrm{aE}}$ & $0.120 \pm 0.001^{\mathrm{cE}}$ & $0.141 \pm 0.002^{\mathrm{bE}}$ & $0.070 \pm 0.005^{\mathrm{eE}}$ & $0.080 \pm 0.004^{\mathrm{dE}}$ \\
\hline \multirow{6}{*}{$\mathrm{Se}$} & muscle & $1.80 \pm 0.07^{\mathrm{cE}}$ & $0.73 \pm 0.0^{\mathrm{eE}}$ & $2.71 \pm 0.08^{\mathrm{aD}}$ & $2.19 \pm 0.0^{\mathrm{bC}}$ & $1.50 \pm 0.04^{\mathrm{dE}}$ \\
\hline & gills & $1.03 \pm 0.06^{\mathrm{bF}}$ & $0.57 \pm 0.03^{\mathrm{eF}}$ & $2.66 \pm 0.11^{\mathrm{aE}}$ & $0.88 \pm 0.02^{\mathrm{dF}}$ & $0.94 \pm 0.03^{\mathrm{cF}}$ \\
\hline & stomach & $10.2 \pm 0.1^{\mathrm{aC}}$ & $3.24 \pm 0.10^{\mathrm{bC}}$ & $2.85 \pm 0.14^{\mathrm{cC}}$ & $1.21 \pm 0.02^{\mathrm{eE}}$ & $1.60 \pm 0.02^{\mathrm{dD}}$ \\
\hline & liver & $12.5 \pm 0.2^{\mathrm{aB}}$ & $5.87 \pm 0.015^{\mathrm{dB}}$ & $10.0 \pm 0.1^{\mathrm{bB}}$ & $4.72 \pm 0.06^{\mathrm{eB}}$ & $8.41 \pm 0.35^{\mathrm{cB}}$ \\
\hline & kidney & $14.6 \pm 0.3^{\mathrm{aA}}$ & $6.74 \pm 0.06^{\mathrm{dA}}$ & $11.8 \pm 0.5^{\mathrm{bA}}$ & $4.92 \pm 0.12^{\mathrm{eA}}$ & $9.01 \pm 0.02^{\mathrm{cA}}$ \\
\hline & gonad & $4.34 \pm 0.17^{\mathrm{bD}}$ & $2.33 \pm 0.12^{\mathrm{dD}}$ & $4.80 \pm 0.17^{a}$ & $2.06 \pm 0.06^{\mathrm{eD}}$ & $3.37 \pm 0.16^{\mathrm{cC}}$ \\
\hline
\end{tabular}

SD: standard deviation; LOQ: limit of quantification. The mean \pm SD for elements designated by different lowercase superscript letters are significantly different from other samples in the same column (i.e., between tissues for one species); (Mann-Whitney $\mathrm{U}$ test, $p<0.05$ ). The mean $\pm \mathrm{SD}$ for elements designated by different uppercase superscript letters are significantly different from other samples in the same row (i.e., between species); (Mann-Whitney $\mathrm{U}$ test, $p<0.05)$. LOQ $\left(\mathrm{mg} \mathrm{kg}^{-1}\right)$ : Cd (0.013), Li (0.092), Mo (0.034) and Ni (0.067).

Table 2. Concentrations of trace elements in fish tissues from the Todos os Santos Bay, Bahia, Brazil (period S2: Dec/2011-Jan/2012)

\begin{tabular}{|c|c|c|c|c|c|}
\hline \multirow{2}{*}{ Element } & \multirow{2}{*}{ Tissue } & \multicolumn{4}{|c|}{ Concentration of elements in species / ( $\mathrm{mg} \mathrm{kg}^{-1}$ dry weight $), \mathrm{n}=3$} \\
\hline & & C. latus & A. rhomboidalis & L. synagris & S. guachancho \\
\hline \multirow{6}{*}{ As } & muscle & $2.38 \pm 0.08^{\mathrm{cD}}$ & $1.28 \pm 0.04^{\mathrm{dD}}$ & $2.73 \pm 0.21^{\mathrm{bE}}$ & $5.17 \pm 0.03^{\mathrm{aD}}$ \\
\hline & gills & $3.69 \pm 0.20^{\mathrm{cA}}$ & $2.83 \pm 0.09^{\mathrm{cC}}$ & $18.57 \pm 0.59^{\mathrm{aB}}$ & $13.01 \pm 0.59^{\mathrm{bA}}$ \\
\hline & stomach & $3.53 \pm 0.12^{\mathrm{cC}}$ & $7.62 \pm 0.05^{\mathrm{cA}}$ & $27.31 \pm 1.50^{\mathrm{aA}}$ & $12.37 \pm 0.24^{\mathrm{bA}}$ \\
\hline & liver & $7.43 \pm 0.46^{\mathrm{cE}}$ & $9.08 \pm 0.06^{\mathrm{dA}}$ & $16.42 \pm 0.42^{\mathrm{aC}}$ & $13.7 \pm 0.21^{\mathrm{bA}}$ \\
\hline & kidney & $4.69 \pm 0.18^{\mathrm{cB}}$ & $4.24 \pm 0.12^{\mathrm{cA}}$ & $9.79 \pm 0.02^{\mathrm{bD}}$ & $11.33 \pm 0.38^{\mathrm{aB}}$ \\
\hline & gonad & $5.00 \pm 0.18^{\mathrm{cB}}$ & $7.78 \pm 0.16^{\mathrm{dB}}$ & $14.02 \pm 0.52^{\mathrm{aB}}$ & $8.38 \pm 0.11^{\mathrm{bC}}$ \\
\hline \multirow{6}{*}{$\mathrm{Cd}$} & muscle & $<$ LOQ & $<$ LOQ & $<\mathrm{LOQ}$ & $<\mathrm{LOQ}$ \\
\hline & gills & $0.127 \pm 0.007^{\mathrm{bC}}$ & $<$ LOQ & $0.248 \pm 0.01^{\mathrm{aB}}$ & $<$ LOQ \\
\hline & stomach & $1.12 \pm 0.01^{\mathrm{bA}}$ & $<\mathrm{LOQ}$ & $0.159 \pm 0.007^{\mathrm{aC}}$ & $0.171 \pm 0.008^{\mathrm{aA}}$ \\
\hline & liver & $0.961 \pm 0.024^{\mathrm{cB}}$ & $<$ LOQ & $0.481 \pm 0.003^{\mathrm{aA}}$ & $0.540 \pm 0.020^{\mathrm{bB}}$ \\
\hline & kidney & $0.072 \pm 0.003^{\mathrm{bD}}$ & $<\mathrm{LOQ}$ & $0.047 \pm 0.001^{\mathrm{bD}}$ & $<\mathrm{LOQ}$ \\
\hline & gonad & $<\mathrm{LOQ}$ & $<$ LOQ & $<\mathrm{LOQ}$ & $<0.014$ \\
\hline \multirow{6}{*}{$\mathrm{Cr}$} & muscle & $0.43 \pm 0.01^{\mathrm{cC}}$ & $0.61 \pm 0.01^{\mathrm{bF}}$ & $0.58 \pm 0.01^{\mathrm{bE}}$ & $1.06 \pm 0.06^{\mathrm{aE}}$ \\
\hline & gills & $0.55 \pm 0.01^{\mathrm{dA}}$ & $1.63 \pm 0.03^{\mathrm{bC}}$ & $1.43 \pm 0.09^{\mathrm{cD}}$ & $1.98 \pm 0.11^{\mathrm{aC}}$ \\
\hline & stomach & $0.44 \pm 0.0^{\mathrm{dBC}}$ & $1.54 \pm 0.07^{\mathrm{cD}}$ & $1.67 \pm 0.00^{\mathrm{bC}}$ & $1.81 \pm 0.04^{\mathrm{aC}}$ \\
\hline & liver & $0.45 \pm 0.02^{\mathrm{dB}}$ & $1.89 \pm 0.03^{\mathrm{bB}}$ & $1.64 \pm 0.02^{\mathrm{cC}}$ & $2.29 \pm 0.11^{\mathrm{aB}}$ \\
\hline & kidney & $0.35 \pm 0.02^{\mathrm{cD}}$ & $2.21 \pm 0.01^{\mathrm{bA}}$ & $2.22 \pm 0.03^{\mathrm{bA}}$ & $3.22 \pm 0.08^{\mathrm{aA}}$ \\
\hline & gonad & $0.26 \pm 0.01^{\mathrm{dE}}$ & $1.10 \pm 0.01^{\mathrm{cE}}$ & $1.80 \pm 0.06^{\mathrm{aB}}$ & $1.44 \pm 0.07^{\mathrm{bD}}$ \\
\hline \multirow{6}{*}{$\mathrm{Cu}$} & muscle & $1.30 \pm 0.10^{\mathrm{aF}}$ & $0.45 \pm 0.02^{\mathrm{bE}}$ & $0.33 \pm 0.01^{\mathrm{bcD}}$ & $0.18 \pm 0.01^{\mathrm{cC}}$ \\
\hline & gills & $3.41 \pm 0.21^{\mathrm{aD}}$ & $2.58 \pm 0.10^{\mathrm{bC}}$ & $3.12 \pm 0.20^{\mathrm{aC}}$ & $1.14 \pm 0.05^{\mathrm{cC}}$ \\
\hline & stomach & $4.74 \pm 0.18^{\mathrm{bA}}$ & $2.44 \pm 0.10^{\mathrm{dCD}}$ & $6.44 \pm 0.21^{\mathrm{bB}}$ & $15.85 \pm 0.26^{\mathrm{aB}}$ \\
\hline & liver & $6.82 \pm 0.09^{\mathrm{bA}}$ & $8.14 \pm 0.18^{\mathrm{bA}}$ & $9.01 \pm 0.30^{\mathrm{bA}}$ & $28.12 \pm 1.65^{\mathrm{aA}}$ \\
\hline & kidney & $3.92 \pm 0.04^{\mathrm{cC}}$ & $4.11 \pm 0.02^{\mathrm{bB}}$ & $3.16 \pm 0.08^{\mathrm{dC}}$ & $13.47 \pm 0.07^{\mathrm{aB}}$ \\
\hline & gonad & $1.86 \pm 0.05^{\mathrm{cE}}$ & $2.10 \pm 0.00^{\mathrm{bD}}$ & $2.87 \pm 0.18^{\mathrm{aC}}$ & $2.82 \pm 0.04^{\mathrm{aC}}$ \\
\hline
\end{tabular}


Table 2. Concentrations of trace elements in fish tissues from the Todos os Santos Bay, Bahia, Brazil (period S2: Dec/2011-Jan/2012) (cont.)

\begin{tabular}{|c|c|c|c|c|c|}
\hline \multirow{6}{*}{$\mathrm{Li}$} & muscle & $<\mathrm{LOQ}$ & $<\mathrm{LOQ}$ & $<\mathrm{LOQ}$ & $<$ LOQ \\
\hline & gills & $0.640 \pm 0.042^{\mathrm{dA}}$ & $1.38 \pm 0.05^{\mathrm{aA}}$ & $0.833 \pm 0.043^{\mathrm{cB}}$ & $1.27 \pm 0.01^{\mathrm{bA}}$ \\
\hline & stomach & $0.571 \pm 0.020^{\mathrm{cB}}$ & $0.091 \pm 0.002^{\mathrm{dC}}$ & $0.790 \pm 0.006^{\mathrm{bA}}$ & $0.850 \pm 0.023^{\mathrm{aB}}$ \\
\hline & liver & $0.154 \pm 0.011^{\mathrm{cC}}$ & $0.142 \pm 0.001^{\mathrm{cB}}$ & $0.283 \pm 0.011^{\mathrm{bC}}$ & $0.329 \pm 0.008^{\mathrm{aC}}$ \\
\hline & kidney & $<$ LOQ & $<$ LOQ & $<$ LOQ & $<$ LOQ \\
\hline & gonad & $<$ LOQ & $<\mathrm{LOQ}$ & $<\mathrm{LOQ}$ & $<$ LOQ \\
\hline \multirow{6}{*}{$\mathrm{Mn}$} & muscle & $0.11 \pm 0.01^{\mathrm{dD}}$ & $0.31 \pm 0.01^{\mathrm{aF}}$ & $0.16 \pm 0.01^{\mathrm{cD}}$ & $0.21 \pm 0.01^{\mathrm{bF}}$ \\
\hline & gills & $18.0 \pm 0.7^{\mathrm{dA}}$ & $77.9 \pm 0.8^{\mathrm{aA}}$ & $29.2 \pm 0.4^{\mathrm{cA}}$ & $35.8 \pm 1.4^{\mathrm{bA}}$ \\
\hline & stomach & $1.59 \pm 0.08^{\mathrm{cC}}$ & $30.6 \pm 0.5^{\mathrm{aB}}$ & $3.54 \pm 0.13^{\mathrm{cB}}$ & $25.6 \pm 0.4^{\mathrm{bB}}$ \\
\hline & liver & $4.07 \pm 0.15^{\mathrm{B}}$ & $5.35 \pm 0.11^{\mathrm{bC}}$ & $3.62 \pm 0.06^{\mathrm{dB}}$ & $7.67 \pm 0.36^{\mathrm{aC}}$ \\
\hline & kidney & $1.32 \pm 0.08^{\mathrm{cCD}}$ & $4.33 \pm 0.02^{\mathrm{aD}}$ & $3.80 \pm 0.02^{\mathrm{bB}}$ & $0.87 \pm 0.04^{\mathrm{dE}}$ \\
\hline & gonad & $1.34 \pm 0.07^{\mathrm{bCD}}$ & $1.13 \pm 0.02^{\mathrm{cE}}$ & $1.41 \pm 0.02^{\mathrm{bC}}$ & $1.73 \pm 0.10^{\mathrm{aD}}$ \\
\hline \multirow{6}{*}{ Mo } & muscle & $<\mathrm{LOQ}$ & $<\mathrm{LOQ}$ & $<\mathrm{LOQ}$ & $<\mathrm{LOQ}$ \\
\hline & gills & $0.045 \pm 0.003^{\mathrm{bD}}$ & $0.042 \pm 0.001^{\mathrm{cD}}$ & $0.045 \pm 0.002^{\mathrm{cD}}$ & $0.089 \pm 0.003^{\mathrm{aD}}$ \\
\hline & stomach & $0.153 \pm 0.008^{\mathrm{cB}}$ & $0.269 \pm 0.013^{\mathrm{aC}}$ & $0.108 \pm 0.001^{\mathrm{dC}}$ & $0.249 \pm 0.011^{\mathrm{bB}}$ \\
\hline & liver & $0.587 \pm 0.022^{\mathrm{bA}}$ & $0.740 \pm 0.005^{\mathrm{aB}}$ & $0.500 \pm 0.003^{\mathrm{cA}}$ & $0.580 \pm 0.054^{\mathrm{dA}}$ \\
\hline & kidney & $0.136 \pm 0.015^{\mathrm{cC}}$ & $1.24 \pm 0.01^{\mathrm{cA}}$ & $0.209 \pm 0.002^{\mathrm{bB}}$ & $0.176 \pm 0.010^{\mathrm{aC}}$ \\
\hline & gonad & $<$ LOQ & $<$ LOQ & $<\mathrm{LOQ}$ & $<$ LOQ \\
\hline \multirow{6}{*}{$\mathrm{Ni}$} & muscle & $<\mathrm{LOQ}$ & $<\mathrm{LOQ}$ & $<\mathrm{LOQ}$ & $<\mathrm{LOQ}$ \\
\hline & gills & $1.02 \pm 0.04^{\mathrm{dB}}$ & $4.50 \pm 0.14^{\mathrm{aC}}$ & $3.35 \pm 0.30^{\mathrm{cB}}$ & $3.65 \pm 0.11^{\mathrm{bB}}$ \\
\hline & stomach & $0.94 \pm 0.06^{\mathrm{cC}}$ & $2.55 \pm 0.20^{\mathrm{aD}}$ & $1.13 \pm 0.04^{\mathrm{bD}}$ & $1.15 \pm 0.07^{\mathrm{bC}}$ \\
\hline & liver & $0.34 \pm 0.02^{\mathrm{cD}}$ & $13.33 \pm 0.17^{\mathrm{aB}}$ & $1.92 \pm 0.05^{\mathrm{bC}}$ & $0.270 \pm 0.003^{\mathrm{dD}}$ \\
\hline & kidney & $1.81 \pm 0.09^{\mathrm{dA}}$ & $15.57 \pm 0.12^{\mathrm{aA}}$ & $4.53 \pm 0.04^{\mathrm{cA}}$ & $4.76 \pm 0.21^{\mathrm{bA}}$ \\
\hline & gonad & $0.090 \pm 0.009^{\mathrm{dE}}$ & $0.23 \pm 0.002^{\mathrm{bE}}$ & $0.75 \pm 0.02^{\mathrm{aE}}$ & $0.150 \pm 0.003^{\mathrm{cE}}$ \\
\hline \multirow{6}{*}{$\mathrm{Pb}$} & muscle & $<\mathrm{LOQ}$ & $0.082 \pm 0.003^{\mathrm{bC}}$ & $0.096 \pm 0.003^{\mathrm{aC}}$ & $<\mathrm{LOQ}$ \\
\hline & gills & $<\mathrm{LOQ}$ & $0.600 \pm 0.014^{\mathrm{aA}}$ & $0.477 \pm 0.012^{\mathrm{bB}}$ & $<\mathrm{LOQ}$ \\
\hline & stomach & $<\mathrm{LOQ}$ & $0.528 \pm 0.020^{\mathrm{aB}}$ & $0.475 \pm 0.009^{\mathrm{bB}}$ & $<\mathrm{LOQ}$ \\
\hline & liver & $<\mathrm{LOQ}$ & $<\mathrm{LOQ}$ & $0.502 \pm 0.006^{\mathrm{A}}$ & $<\mathrm{LOQ}$ \\
\hline & kidney & $<\mathrm{LOQ}$ & $<\mathrm{LOQ}$ & $<\mathrm{LOQ}$ & $<\mathrm{LOQ}$ \\
\hline & gonad & $<\mathrm{LOQ}$ & $<\mathrm{LOQ}$ & $<\mathrm{LOQ}$ & $<\mathrm{LOQ}$ \\
\hline \multirow{6}{*}{$\mathrm{Se}$} & muscle & $1.03 \pm 0.05^{\mathrm{bF}}$ & $1.24 \pm 0.01^{\mathrm{aF}}$ & $1.26 \pm 0.03^{\mathrm{aF}}$ & $0.96 \pm 0.06^{\mathrm{cF}}$ \\
\hline & gills & $1.44 \pm 0.03^{\mathrm{dE}}$ & $1.74 \pm 0.06^{\mathrm{cE}}$ & $2.57 \pm 0.08^{\mathrm{bE}}$ & $4.45 \pm 0.17^{\mathrm{aD}}$ \\
\hline & stomach & $3.90 \pm 0.08^{\mathrm{aC}}$ & $1.93 \pm 0.05^{\mathrm{dD}}$ & $3.03 \pm 0.01^{\mathrm{cD}}$ & $3.44 \pm 0.12^{\mathrm{bE}}$ \\
\hline & liver & $6.06 \pm 0.31^{\mathrm{bB}}$ & $3.54 \pm 0.07^{\mathrm{cB}}$ & $6.99 \pm 0.22^{\mathrm{aB}}$ & $6.13 \pm 0.05^{\mathrm{bB}}$ \\
\hline & kidney & $19.4 \pm 0.64^{\mathrm{aA}}$ & $4.73 \pm 0.05^{\mathrm{dA}}$ & $8.73 \pm 0.09^{\mathrm{cA}}$ & $12.6 \pm 0.1^{\mathrm{bA}}$ \\
\hline & gonad & $2.06 \pm 0.04^{\mathrm{dD}}$ & $2.33 \pm 0.02^{\mathrm{cC}}$ & $4.23 \pm 0.21^{\mathrm{bC}}$ & $5.71 \pm 0.06^{\mathrm{aC}}$ \\
\hline
\end{tabular}

SD: standard deviation; LOQ: limit of quantification. The mean \pm SD for elements designated by different lowercase superscript letters are significantly different from other samples in the same column (i.e., between tissues for one species). (Mann-Whitney $\mathrm{U}$ test, $p<0.05$ ). The mean $\pm \mathrm{SD}$ for elements designated by different uppercase superscript letters are significantly different from other samples in the same row (i.e., between species). (Mann-Whitney $\mathrm{U}$ test, $p<0.05)$. LOQ $\left(\mathrm{mg} \mathrm{kg}^{-1}\right)$ : Cd (0.013), Li (0.092), Mo (0.034), Ni (0.067) and Pb (0.042).

$1.46-55.9 \mathrm{mg} \mathrm{kg}^{-1}$ in stomach, $3.36-77.9 \mathrm{mg} \mathrm{kg}^{-1}$ in gills, $3.00-16.5 \mathrm{mg} \mathrm{kg}^{-1}$ in liver, $0.87-5.25 \mathrm{mg} \mathrm{kg}^{-1}$ in kidney and $1.09-3.83 \mathrm{mg} \mathrm{kg}^{-1}$ in gonads. The highest concentrations of $\mathrm{Mn}$ were found in the gill $\left(77.9 \pm 0.8 \mathrm{mg} \mathrm{kg}^{-1}\right)$ and stomach $\left(55.9 \pm 2.9 \mathrm{mg} \mathrm{kg}^{-1}\right)$ tissues of $A$. rhomboidalis.
The maximum Mn level in fish permitted for human consumption is $1 \mu \mathrm{g} \mathrm{g}^{-1}$ according to the World Health Organization (WHO) guideline..$^{24}$ For the samples analyzed in this study, only the Mn levels $\left(1.37 \mathrm{mg} \mathrm{kg}^{-1}\right)$ in the A. rhomboidalis fish species were found to exceed the 
permissible limits. Manganese concentrations reported by previous research ranged from 0.07 to $7.3 \mathrm{mg} \mathrm{kg}^{-1}$ in the muscle of fish captured along the Rio de Janeiro State coast, Brazil. ${ }^{3}$

Copper is vital for the biological transfer of electrons, for the synthesis of red blood cells and for the preservation of nervous system structure and function. However, high $\mathrm{Cu}$ intake is known to result in adverse health effects. The provisional tolerable daily intake (PTDI) for copper, sets as a limit for metal intake based on body weight for an average adult ( $60 \mathrm{~kg}$ body weight), is $3 \mathrm{mg} .{ }^{25}$ The observed $\mathrm{Cu}$ concentrations varied from 0.17 to $1.30 \mathrm{mg} \mathrm{kg}^{-1}$ in muscle, 1.14 to $6.14 \mathrm{mg} \mathrm{kg}^{-1}$ in gills, 2.44 to $15.85 \mathrm{mg} \mathrm{kg}^{-1}$ in stomach, 4.87 to $28.12 \mathrm{mg} \mathrm{kg}^{-1}$ in liver, 2.64 to $13.47 \mathrm{mg} \mathrm{kg}^{-1}$ in kidney and 1.67 to $2.87 \mathrm{mg} \mathrm{kg}^{-1}$ in gonads.

The highest $\mathrm{Cu}$ concentration $\left(28.12 \mathrm{mg} \mathrm{kg}^{-1}\right)$ was found in liver tissues of S. guachancho sampled during the S2 period. A similar trend was found in a recent work for fish species collected from the aquatic ecosystems of Moldova, Ukraine. ${ }^{10}$ Previous analyses of muscle tissue from other Brazilian fish species demonstrated $\mathrm{Cu}$ values that ranged from 0.03 to $23.5 \mathrm{mg} \mathrm{kg}^{-1}$. 3

Nickel is also essential for normal growth and reproduction in mammals but is carcinogenic when consumed in exceedingly high amounts. ${ }^{26}$ The minimum and maximum concentrations were found to range from $1.02-4.76 \mathrm{mg} \mathrm{kg}^{-1}$ in gills, $0.88-3.76 \mathrm{mg} \mathrm{kg}^{-1}$ in stomach, $0.34-13.33 \mathrm{mg} \mathrm{kg}^{-1}$ in liver, $1.81-15.57 \mathrm{mg} \mathrm{kg}^{-1}$ in kidney and 0.070 to $0.75 \mathrm{mg} \mathrm{kg}^{-1}$ in gonads. The highest values of $\mathrm{Ni}$ were in the kidney $\left(15.57 \mathrm{mg} \mathrm{kg}^{-1}\right)$ and liver (13.33 $\mathrm{mg} \mathrm{kg}^{-1}$ ) of A. rhomboidalis sampled during S2.

The concentrations of $\mathrm{Ni}$ in muscle were below the LOQ values in all analyzed samples. A comparison of the mean $\mathrm{Ni}$ values with previous reports suggests that the results in the present study ${ }^{26,27}$ are generally lower than those in other studies.

Chromium is an essential mineral and has been implicated in carbohydrate, lipid, and protein metabolism. ${ }^{28}$ The $\mathrm{Cr}$ concentrations for the two sampling periods ranged from $0.38-1.30 \mathrm{mg} \mathrm{kg}^{-1}$ in muscle, $0.44-2.30 \mathrm{mg} \mathrm{kg}^{-1}$ in stomach, $0.55-1.98 \mathrm{mg} \mathrm{kg}^{-1}$ in gills, $0.45-5.46 \mathrm{mg} \mathrm{kg}^{-1}$ in liver, $0.35-6.05 \mathrm{mg} \mathrm{kg}^{-1}$ in kidney and $0.26-1.44 \mathrm{mg} \mathrm{kg}^{-1}$ in gonads. The highest $\mathrm{Cr}$ concentrations were found in kidney tissue followed by liver for S. cavalla. Muscle samples from two fish species, L. synagris and S. guachancho, exceeded the Brazilian standard for consumption, $0.1 \mathrm{mg} \mathrm{kg}^{-1} .^{29}$

Selenium is an essential micronutrient that is vital to biological systems in small amounts, but there is a narrow exposure range between the essential dose and toxicity in fish. ${ }^{30}$ The measured levels of Se ranged from $0.73-2.19 \mathrm{mg} \mathrm{kg}^{-1}$ in muscle, $1.21-10.2 \mathrm{mg} \mathrm{kg}^{-1}$ in stomach,
0.57-4.45 mg kg-1 in gills, $3.54-12.5 \mathrm{mg} \mathrm{kg}^{-1}$ in liver, $4.73-19.4 \mathrm{mg} \mathrm{kg}^{-1}$ in kidney and $2.06-5.71 \mathrm{mg} \mathrm{kg}^{-1}$ in gonads.

The highest concentrations of Se were found in kidney and liver, which are known target organs for Se because they function in Se metabolism. Mean selenium concentrations reported by previous research in the kidney and liver tissues of Capoeta trutta collected from four sites of Keban Dam Lake, Turkey, ${ }^{30}$ were lower than our own results for fish samples from Todos os Santos Bay. The Se concentration range in muscle tissue has been reported as $0.002-0.3 \mathrm{mg} \mathrm{kg}^{-1}$ and $2.046-5.167 \mathrm{mg} \mathrm{kg}^{-1}$ for different fish species and tissues. 3.31

Molybdenum tissue content ranged from $0.038-0.269 \mathrm{mg} \mathrm{kg}^{-1}$ in stomach, $0.037-0.089 \mathrm{mg} \mathrm{kg}^{-1}$ in gills, $0.236-1.17 \mathrm{mg} \mathrm{kg}^{-1}$ in liver and $0.136-1.29 \mathrm{mg} \mathrm{kg}^{-1}$ in kidney. The Mo concentrations in muscle and gonad tissues were below the LOQ $\left(0.034 \mathrm{mg} \mathrm{kg}^{-1}\right)$. Liver and kidney tissues demonstrated a high capacity to bioaccumulate Mo. In general, organs involved in metabolism, i.e., gills, liver, and kidney, often accumulate greater amounts of trace elements than muscle. No previous reports of Mo concentrations in fish samples could be found to compare with the results of the present study.

Lithium content in the analyzed fish samples ranged from $0.17-1.19 \mathrm{mg} \mathrm{kg}^{-1}$ in stomach, $0.10-0.89 \mathrm{mg} \mathrm{kg}^{-1}$ in gills and $0.13-0.22 \mathrm{mg} \mathrm{kg}^{-1}$ in liver. The Li concentrations in muscle, kidney and gonad tissues were below the LOQ (0.092 $\left.\mathrm{mg} \mathrm{kg}^{-1}\right)$. Detectable $\mathrm{Li}$ concentrations were found in the stomach and gills, which suggests that the main $\mathrm{Li}$ exposure route in fish is via food intake. Few studies have reported Li concentrations in fish tissues. Comparison with the mean $\mathrm{Li}$ values in previous reports suggests that the results of the present study are generally lower than those reported in other studies. ${ }^{32}$ Guérin et al..$^{32}$ measured a range of $\mathrm{Li}$ concentrations ( $\mathrm{mg} \mathrm{kg}^{-1}$ wet weight) in liver and gill tissues: liver ( 0.15 to 0.57$)$, gill (0.22 to 0.30$).^{2}$ In the present study, the measured concentrations were $\left(\mathrm{mg} \mathrm{kg}^{-1}\right.$ wet weight) 0.030 to 0.073 in liver and 0.023 to 0.317 in gill tissue.

Cadmium is a non-essential element found in foods and natural waters with potential toxicity to fishes even at low levels. The $\mathrm{Cd}$ concentrations in the fish tissues analyzed in this study were $0.159-1.366 \mathrm{mg} \mathrm{kg}^{-1}$ in stomach, $0.093-0.525 \mathrm{mg} \mathrm{kg}^{-1}$ in gills, $0.401-0.961 \mathrm{mg} \mathrm{kg}^{-1}$ in liver, and $0.047-0.081 \mathrm{mg} \mathrm{kg}^{-1}$ in kidney. Cd concentrations in muscle and gonad tissues were below the LOQ. The highest $\mathrm{Cd}$ concentrations were found in the stomach and liver tissues of C. latus. Several studies have reported Cd levels in muscle tissue. ${ }^{30,33} \mathrm{Cd}$ levels found in the liver were also comparable with previously reported findings from fish native to Turkish seas ${ }^{33}$ and Danube River, Serbia. ${ }^{9}$ In other 
studies of Brazilian fish, the Cd concentrations in muscle tissue ranged from $<0.003$ to $0.047 \mathrm{mg} \mathrm{kg}^{-1}$ and 0.014 to $0.123 \mathrm{mg} \mathrm{kg}^{-1}$. 3,6

Lead is also a non-essential element, and it is well documented that $\mathrm{Pb}$ can cause neurotoxicity, nephrotoxicity, and many other adverse health effects. ${ }^{34}$ The lead concentration for all samples collected in the first summer period was below the limit of quantification for the method $\left(<0.042 \mathrm{mg} \mathrm{kg}^{-1}\right)$. The concentrations of $\mathrm{Pb}$ in the analyzed samples from the second sampling period ranged from $0.475-0.528 \mathrm{mg} \mathrm{kg}^{-1}$ in stomach, $0.477-0.600 \mathrm{mg} \mathrm{kg}^{-1}$ in gills and $<0.042-0.502 \mathrm{mg} \mathrm{kg}^{-1}$ in liver. Lead was detected only in tissues of two species (A. rhomboidalis and L. synagris). Researchers reported higher $\mathrm{Pb}$ concentrations in liver tissues than those measured in the present study. ${ }^{33}$ Previous analyses of different fish species from Brazil demonstrated mean concentrations of $\mathrm{Pb}$ in muscle tissue that ranged from 0.01 to $0.5 \mathrm{mg} \mathrm{kg}^{-1},{ }^{3}$ and 0.10 to $5.4 \mathrm{mg} \mathrm{kg}^{-1}{ }^{6}$

The measured concentrations of trace elements varied significantly depending on the analyzed tissue $(p<0.05)$. The muscle and gonad tissues contained lower concentrations of trace elements, with levels below LOQ for $\mathrm{Mo}, \mathrm{Li}, \mathrm{Cd}, \mathrm{Pb}$ and $\mathrm{Sb}$. The highest concentrations of trace elements were found in kidney, liver and gill tissues.

The liver demonstrated an increased potential to accumulate various trace elements, contributing significantly to the storage of metals in fish. This potential to preferentially concentrate trace elements in liver over muscle may result from an increased reaction rate with metallothioneins present in liver. ${ }^{28,31,35}$

Although gill tissue does not maintain high metabolic activity, it still showed a relevant accumulation of most of the studied analytes, including $\mathrm{Mn}, \mathrm{Li}$ and Cd. This can be explained by adsorption of trace elements onto the gill surface, resulting in increased concentrations of trace elements. Thus, analyte concentrations in gill may be an indicative of the exposure route for trace elements, i.e., exposure to polluted aquatic environments.

The muscle does not actively accumulate trace elements because of its metabolic rate ${ }^{36}$ However, high trace element concentrations in soft tissues (muscles and skin) have been reported for fish in polluted regions and, in several cases, these concentrations have exceeded acceptable levels. Therefore, the evaluation of trace element concentrations in muscle and regulation of these concentrations is important for generating estimates of the quantities of metals that humans may consume. ${ }^{37}$

For all the tissues analyzed, the contaminant element concentrations were significantly different between the two sampling periods (Tables 1 and 2), except for the concentration of arsenic in the gonads of $C$. latus (Table 2).

Relationships between the concentrations of trace elements in all tissues revealed that $\mathrm{As}$, Se and $\mathrm{Li}$ concentrations were not significantly associated with other elements. A significant correlation was observed mainly involving pairs of elements with $\mathrm{Ni}, \mathrm{Mn}$ or Cd. Significant correlations were found as follows: $\mathrm{Cu}-\mathrm{Ni}(0.70), \mathrm{Mn}-\mathrm{Cr}$ (-0.82), Mn-Ni (0.70), Cr-Ni (-0.64), Ni-Cd (0.86), Ni-Pb $(-0.69)$, Mo-Cd (0.76) and $\mathrm{Cd}-\mathrm{Pb}(-0.69)$.

Relationships between trace element concentrations in tissues revealed a high correlation involving liver and kidney tissues (Table 3), mainly for the potential of contaminating chemical elements (As, $\mathrm{Cd}, \mathrm{Cr}$ and $\mathrm{Ni}$ ). This high correlation may be related to the function of these organs in the body's detoxification process.

Table 3. Relationships between trace element concentrations in tissues

\begin{tabular}{|c|c|c|c|c|c|c|}
\hline & Muscle & Stomach & Liver & Gills & Kidney & Gonad \\
\hline Muscle & - & ns & ns & ns & $\mathrm{ns}$ & $\mathrm{ns}$ \\
\hline Stomach & & - & $\begin{array}{l}\text { As: } 0.87 \text {; Se: } 0.74 \\
\text { Cd: } 0.86 \text {; Ni: } 0.69 \\
\text { Mn: } 0.85 \text {; Cu: } 0.93\end{array}$ & $\begin{array}{c}\text { As: } 0.94 \\
\text { Cd: }-0.73 \\
\text { Cr: } 0.90\end{array}$ & $\begin{array}{l}\text { Ni: } 0.73 \\
\text { Cu: } 0.90\end{array}$ & Mn: 0.71 \\
\hline Liver & & & - & $\begin{array}{c}\text { As: } 0.94 \\
\text { Cd: }-0.84\end{array}$ & $\begin{array}{l}\text { As: } 0.94 \\
\text { Ni: } 0.93 \\
\text { Cr: } 0.94 \\
\text { Cu: } 0.86\end{array}$ & $\begin{array}{l}\text { As: } 0.96 \\
\text { Se: } 0.66 \\
\text { Mn: } 0.67\end{array}$ \\
\hline Gills & & & & - & $\begin{array}{l}\text { As: } 0.87 \\
\text { Ni: } 0.65\end{array}$ & $\begin{array}{l}\text { As: } 0.92 \\
\text { Ni: } 0.73 \\
\text { Se: } 0.72 \\
\text { Cr: } 0.65\end{array}$ \\
\hline Kidney & & & & & - & As: 0.64 \\
\hline Gonad & & & & & & - \\
\hline
\end{tabular}


Research has suggested that a consistent association between metals indicates a similarity in their biochemical mechanisms in the tissue. ${ }^{38}$ However, studies reporting the relationship between the chemical elements in aquatic organism tissues are still incipient. ${ }^{39}$

In Brazil, according to the Agência Nacional de Vigilância Sanitária (ANVISA), the permissible limits for $\mathrm{Cr}$ and $\mathrm{Se}$ in fish designated for human consumption are 0.10 and $0.30 \mathrm{mg} \mathrm{kg}^{-1}$ of wet weight, respectively, ${ }^{40}$ and for $\mathrm{Cd}$ and $\mathrm{Pb}$ are $0.05-0.30$ and $0.30 \mathrm{mg} \mathrm{kg}^{-1}$ of wet weight, respectively. ${ }^{29}$ The European Commission (EC) has set upper limits of 0.05 and $0.3 \mathrm{mg} \mathrm{kg}^{-1}$ of wet weight for $\mathrm{Cd}$ and $\mathrm{Pb}$, respectively. ${ }^{41}$ The Food and Agriculture Organization (FAO) established limits for $\mathrm{Cd}$ and $\mathrm{Pb}$ in fish for human consumption of 0.5 and $0.05 \mathrm{mg} \mathrm{kg}^{-1}$ of wet weight, respectively. ${ }^{42}$ To compare the data obtained in this study with the prescribed limits, all muscle concentrations were standardized on a wet weight basis.

Comparing the trace element concentrations measured in muscle with the maximum values established by ANVISA (Table 4), the concentrations of $\mathrm{Cu}, \mathrm{Cr}, \mathrm{Se}, \mathrm{Ni}$, $\mathrm{Pb}$ and $\mathrm{Cd}$ were all well below the tolerable limits for food. However, analyzed muscle tissues demonstrated concentrations of $\mathrm{Cr}$ and $\mathrm{Se}$ that exceeded these limits. Chromium concentrations were 2 to 3 times greater than the limit for L. synagris and S. guachancho. The measured Se concentrations exceeded the tolerable limits for human consumption in $45 \%$ of the muscle samples for C. latus, A. rhomboidalis, $L$. synagris and $S$. cavalla collected during the S1 period. Se high levels were also found in muscles and viscera of other organisms from the region of the Todos os Santos Bay. ${ }^{39}$

Table 4. Comparing the concentrations of the chemical elements investigated the maximum values allowed by current Brazilian legislation

\begin{tabular}{lcc}
\hline Element & $\begin{array}{c}\text { Brazilian legislation / } \\
\left(\mu \mathrm{g} \mathrm{g}^{-1} \text { wet weight }\right)^{\mathrm{a}}\end{array}$ & $\begin{array}{c}\text { Found concentration range / } \\
\left(\mu \mathrm{g} \mathrm{g}^{-1} \text { wet weight }\right)\end{array}$ \\
\hline $\mathrm{Cu}$ & 30.0 & $0.04-0.25$ \\
$\mathrm{Cr}$ & 0.10 & $0.09-0.30$ \\
$\mathrm{Se}$ & 0.30 & $0.17-0.50$ \\
$\mathrm{Ni}$ & 5.0 & $<0.005$ \\
$\mathrm{~Pb}^{\mathrm{b}}$ & 0.30 & $0.019-0.022$ \\
$\mathrm{Cd}^{\mathrm{b}}$ & $0.05-0.30$ & $<0.001$ \\
$\mathrm{As}^{\mathrm{b}}$ & 1.0 & $0.48-1.19$ \\
\hline
\end{tabular}

${ }^{\mathrm{a}}$ ANVISA, 1965; ${ }^{\mathrm{b} A N V I S A} 2013$.

In addition, all samples collected during the $\mathrm{S} 2$ period demonstrated concentrations that approached the limits. Arsenic concentrations found in muscle exceeded the tolerable limits in $20 \%$ of the samples (L. synagris and
S. guachancho). Importantly, the concentrations of $\mathrm{Cr}$ exceeded the legal limits in $20 \%$ of the samples, and the Se concentrations exceeded the legal limits in nearly half of the samples $(45 \%)$. The presence of these elements in the edible tissues of fish is worrisome because it suggests environmental contamination. Additional studies should be conducted to determine the chemical speciation of these elements because the resultant toxicity is chemical species dependent.

\section{Data evaluation using PCA and HCA}

The experimental data obtained in the two considered periods were evaluated by PCA. A data matrix involving 8 elements as columns and the samples as rows was constructed, being the data auto-scaled because the element concentrations are of different orders of magnitude.

The loadings of the original variables on the first three principal components and the variances explained by each principal component are shown in Table 5.

Table 5. Loading matrix from principal component analysis and total variance explained

\begin{tabular}{lccc}
\hline Variable & PC 1 & PC 2 & PC 3 \\
\hline $\mathrm{Mn}$ & 0.12 & 0.89 & -0.20 \\
$\mathrm{Li}$ & 0.28 & 0.87 & -0.11 \\
$\mathrm{Cu}$ & -0.48 & 0.39 & 0.56 \\
$\mathrm{As}$ & -0.30 & 0.19 & 0.76 \\
$\mathrm{Cr}$ & -0.82 & 0.13 & -0.11 \\
$\mathrm{Ni}$ & -0.74 & 0.15 & -0.44 \\
$\mathrm{Mo}$ & -0.90 & 0.05 & -0.14 \\
$\mathrm{Se}$ & -0.71 & -0.23 & 0.00 \\
Total variance / \% & 36.97 & 22.73 & 14.65 \\
Cumulative variance / \% & 36.97 & 59.69 & 74.34 \\
\hline
\end{tabular}

The data were modeled considering the first three components for a total variance of $74.34 \%$, being that the dominant variables for the first principal component (PC1) are: chromium, molybdenum, nickel and selenium. All these four elements contribute to the major variability shown in the samples, and they are positively correlated, although all with negative loadings. An evaluation of Figures $1 \mathrm{a}$ and $1 \mathrm{~b}$ reveals that the samples of kidneys and livers have the highest concentrations for these four elements.

This observation is possible because liver and kidney samples were clustered in the negative axis of the $\mathrm{PC} 1$ score graph and similarly the variables (molybdenum, chromium, nickel and selenium) are positioned on the negative axis of 

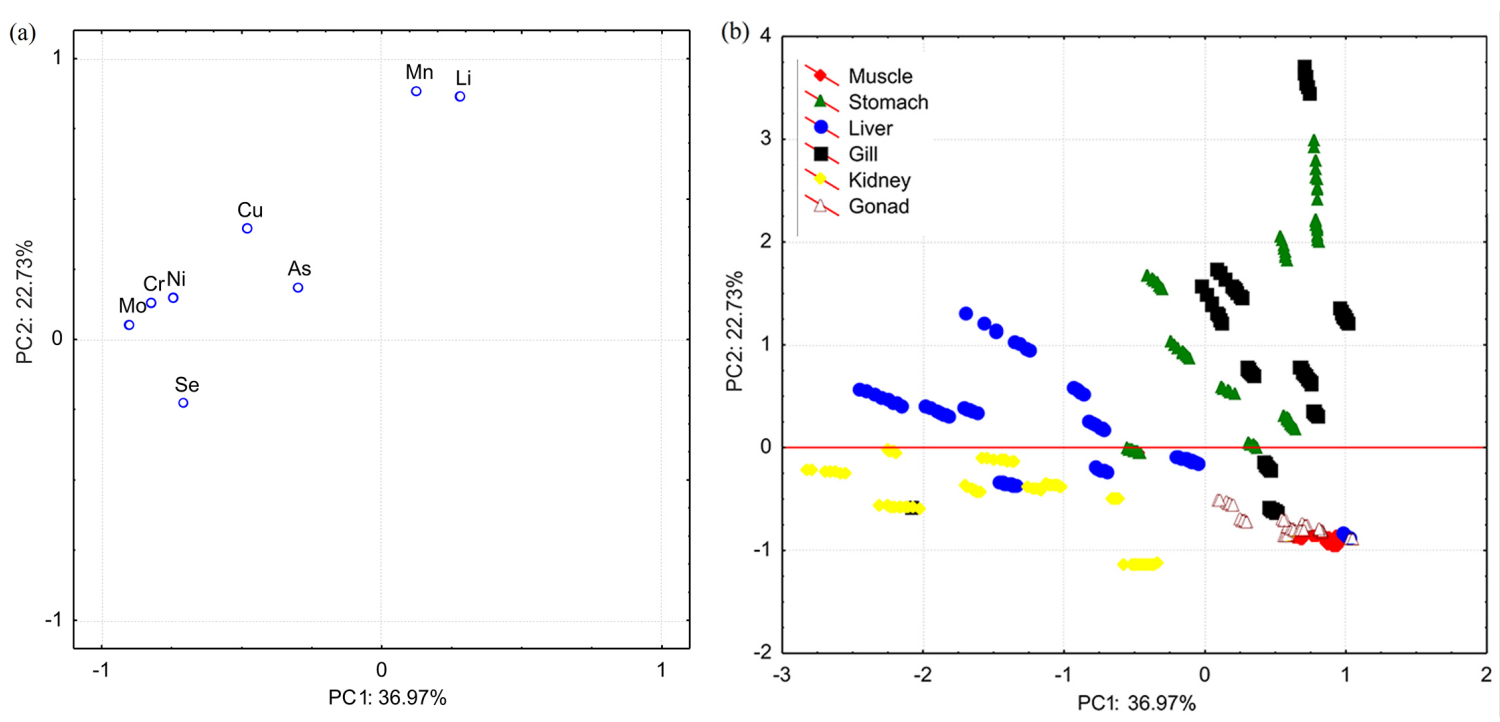

Figure 1. (a) Loading graph of $\mathrm{PC} 1 \times \mathrm{PC} 2$ and (b) score graph of $\mathrm{PC} 1 \times \mathrm{PC} 2$ for fish organ samples.

PC1 in the loading graph. For the same reason, it can be affirmed that gill, gonads, muscle and stomach samples, which are positioned on the positive axis of the PC1 score graph, have low concentrations of these four elements.

The second principal component (PC2) accounts for $22.73 \%$ of the total variance, including lithium and manganese as the dominant variables. Figures $1 \mathrm{a}$ and $1 \mathrm{~b}$ show that some samples of gills and stomachs have the highest concentrations of these two elements. From Figure $1 \mathrm{a}, \mathrm{Mn}$ and $\mathrm{Li}$ are positioned in the positive axis PC2 loading graph, in this way, samples having high concentrations of these elements also will position in the positive axis PC2 score plot.
Considering the loadings of the elements as Table 4, an analysis of the Figure $1 \mathrm{~b}$ shows that the muscle and gonad samples have the lowest concentration of the elements: arsenic, chromium, copper, lithium, manganese, molybdenum, nickel and selenium. These results are compatible with papers published in which fish muscles always exhibited the lower metal concentrations compared with other tissues such as the skin, gills, intestine, liver and kidney. ${ }^{21}$

The experimental data were also evaluated by HCA technique using Ward's method procedure and applying the Euclidean distances. This technique, as can be seen in Figure 2, shows the formation of three great groups. The first

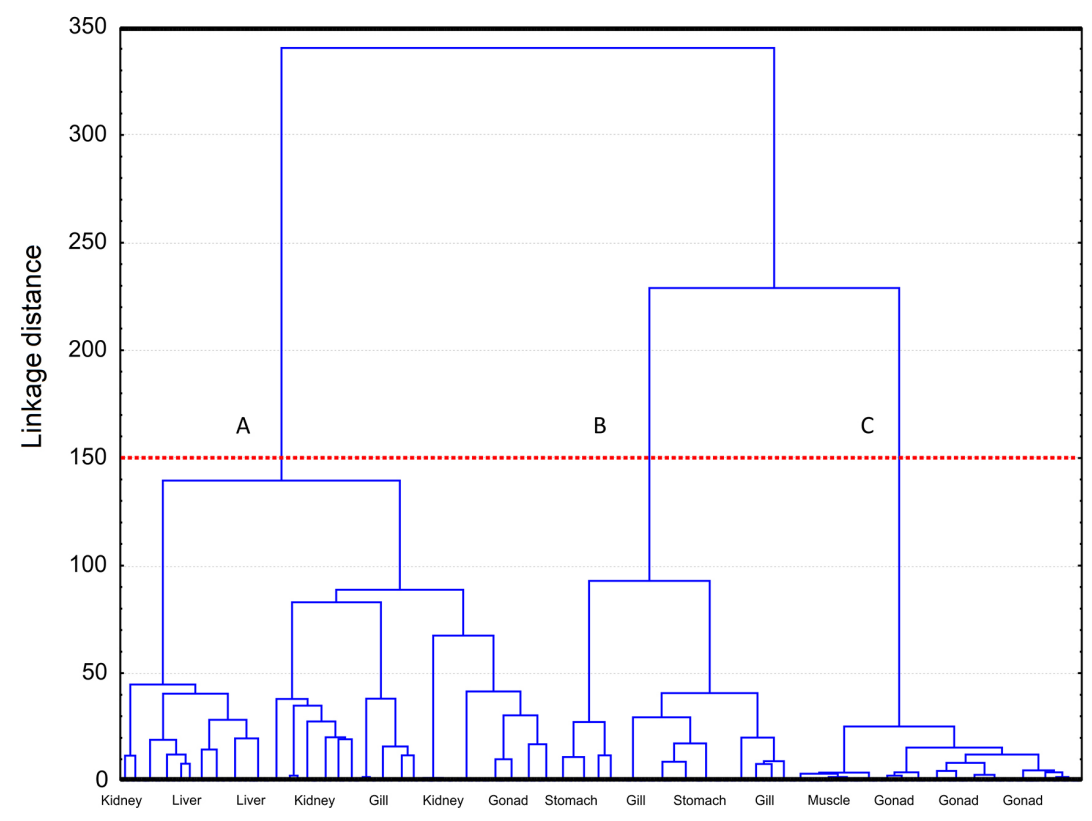

Figure 2. Dendogram of the fish tissue samples: (A) liver and kidney, (B) gill and stomach and (C) muscle and gonad. 
group was formed by liver and kidney samples. A second group involved the gill and stomach samples. The gonad and muscle samples formed the third group. The HCA results are compatible with those found by PCA results.

\section{Conclusions}

To the best of our knowledge, this is the first detailed report of selected trace elements in tissues of fish species from the Todos os Santos Bay, Bahia State, Brazil; therefore, only limited comparisons of our results with other data can be made.

In general, muscle and gonads accumulated the lowest levels of trace elements, and the highest concentrations were found in kidney, liver and gills. Levels of $\mathrm{Cr}, \mathrm{Se}, \mathrm{Cd}$ and $\mathrm{Pb}$ in fish tissues were found to exceed the permissible levels set for food, according to the Brazilian, EC and FAO standards. The levels of $\mathrm{Cd}$ and $\mathrm{Pb}$ in the edible parts of the fish were below the proposed limits for human consumption. Statistically significant differences were observed in the mean trace element values obtained from different fish species and their tissues.

This study also underscores the extreme importance of performing speciation studies and surveillance programs to provide important data regarding fish population health and human consumption.

\section{Acknowledgments}

The authors would like to acknowledge the support of Fundação de Amparo a Pesquisa do Estado da Bahia (FAPESB, Brazil), Conselho Nacional de Desenvolvimento Científico e Tecnológico (CNPq, Brazil), Instituto Nacional de Ciência e Tecnologia (INCT), Energia e Ambiente, Petróleo Brasileiro S. A. (Petrobras, Brazil) and Coordenação de Aperfeiçoamento de Pessoal de Nível Superior (CAPES, Brazil).

\section{References}

1. Food and Agriculture Organization of the United Nations/World Health Organization (FAO/WHO); Report of the Joint FAO/ WHO Expert Consultation on the Risks and Benefits of Fish Consumption; FAO/WHO: Rome, Italy, 2011, p. 50.

2. Guérin, T.; Chekri, R.; Vastel, C.; Sirot, V.; Volatier, J.; Leblanc, J.; Noel, L; Food Chem. 2011, 127, 934.

3. Medeiros, R. J.; Santos, L. M. G.; Freire, A. S.; Santelli, R. E.; Braga, A. M. C. B.; Krauss, T. M.; Jacob, S. C; Food Control 2012, 23, 535 .

4. Azevedo, J. S.; Sarkis, J. E. S.; Hortellani, M. A.; Ladle, R. J.; Water Air Soil Pollut. 2012, 223, 3911.
5. Bilandžić, N.; Sedak, M.; Đokić, M.; Varenina, I.; Kolanović, B. S.; Đurđica Božić, D.; Brstilo, M.; Šimić, B.; J. Food Compos. Anal. 2014, 35, 61.

6. Santos, L. F. P.; Trigueiro, I. N. S.; Lemos, V. A.; Furtunato, D. M. N.; Cardoso, R. C. V.; Food Control 2013, 33, 193.

7. Fraser, M.; Surette, C.; Vaillancourt, C.; Environ. Sci. Pollut. Res.; 2013, 20, 761.

8. Fraser, M.; Surette, C.; Vaillanc, C.; Environ. Sci. Pollut. Res. 2013, 20, 761.

9. Subotić, S.; Jeftić, Z. V.; Spasić, S.; Hegediš, A.; Krpo-Ćetković, J.; Lenhardt, M.; Environ. Sci. Pollut. Res. 2007, 20, 5309.

10. Zubcov, E.; Zubcov, N.; Ene, A.; Biletchi, L.; Environ. Sci. Pollut. Res. 2012, 19, 2238.

11. Bigot, C.; Meile, J.; Kapitan, A.; Montet, D.; Food Control 2015, 48, 123.

12. Di Bella, G.; Lo Turco, V.; Potortì, A. G.; Bua, G. D.; Fede, M. R.; Dugo, G.; J. Food Compos. Anal. 2015, 44, 25.

13. Duedahl-Olesen, L.; Aaslyng, M.; Meinert, L.; Christensen, T.; Jensen, A. H.; Binderup, M.-L.; Food Control 2015, 57, 169.

14. Islam, M. S.; Ahmed, M. K.; Habibullah-Al-Mamun, M.; Masunaga, S.; J. Food Compos. Anal. 2015, 42, 8.

15. Li, L.; Boyd, C. E.; Odom, J.; Food Control 2014, 45, 70.

16. Aquino, F. J. T.; Augusti, R.; Alves, J. O.; Diniz, M. E. R.; Morais, S. A. L.; Alves, B. H. P.; Nascimento, E. A.; Sabino, A. A.; Microchem. J. 2014, 117, 127.

17. Aktas, A. B.; Ozen, B.; Tokatli, F.; Sen, I.; Food Chem. 2014, 161, 104.

18. Calanche, J.; Samayoa, S.; Alonso, V.; Provincial, L.; Roncales, R.; Beltran, J. A.; Food Control 2013, 33, 126.

19. Zaragoza, P.; Fuentes, A.; Fernandez-Segovia, I.; Vivancos, J. L.; Rizo, A.; Ros-Lis, J. V.; Barat, J. M.; Martinez-Manez, R.; Food Chem. 2013, 138, 1374.

20. Liu, X.; Xue, C.; Wang,Y.; Li, Z.; Xue, Y.; Xu, J.; Food Control 2012, 23, 522.

21. Low, K. H.; Zain, S. M.; Abas, M. R.; Food Anal. Methods 2011, 4, 276.

22. Ferreira, S. L. C.; Silva, L. O. B.; Santana, F. A.; Junior, M. M. S.; Matos, G. D.; Santos, W. N. L.; Microchem. J. 2013, 106, 307.

23. Cohen, Y.; Cohen, J. Y.; Statistics and Data with R: an Applied Approach through Examples; Wiley \& Sons: West Sussex, United Kingdom, 2008.

24. World Health Organization (WHO); Heavy MetalsEnvironmental Aspects. Environment Health Criteria Series: Manganese; WHO/IPCS: Geneva, Switzerland, 1981, p. 17.

25. Food and Agriculture Organization of the United Nations/World Health Organization (FAO/WHO); Summary and Conclusions Joint Fao/Who Expert Committee on Food Additives Fifty-third Meeting; FAO/WHO: Rome, Italy, 1999.

26. Sneddon, J.; Rode, P. W.; Hamilton, M. A.; Pingeli, S.; Hagen, J. P.; Appl. Spectrosc. Rev. 2007, 42, 23. 
27. Malik, R. N.; Hashmi, M. Z.; Huma, Y.; Environ. Sci. Pollut. Res. 2014, 21, 1188.

28. Berg, J. M.; Tymoczko, J. L.; Stryer, L.; Bioquímica; Guanabara Koogan: Rio de Janeiro, Brazil, 2004.

29. Agência Nacional de Vigilância Sanitária (ANVISA); Dispõe sobre o Regulamento Técnico MERCOSUL sobre Limites Máximos de Contaminantes Inorgânicos em Alimentos, Resolução RDC No. 42, de 29.08.2013, 2013, http://www.abic.com.br/publique/media/RDC42-2013ContaminantesInorganicos.pdf, accessed in April 2016.

30. Danabas, D.; Ural, M.; Bull. Environ. Contam. Toxicol. 2012, $89,455$.

31. Fallah, A. A.; Saei-Dehkordi, S.; Nematollahi, A.; Jafari, T.; Microchem. J. 2011, 98, 275.

32. Guérin, T.; Chekri, R.; Vastel, C.; Sirot, V.; Volatier, J.; Leblanc, J.; Noel, L.; Food Chem. 2011, 127, 934.

33. Tepe, Y.; Türkmen, M.; Türkmen, A.; Environ. Monit. Assess. 2008, 146, 277.

34. Garcia-Leston, J.; Mendez, J.; Pasaro, E.; Laffon, B.; Environ. Int. 2010, 36, 623.

35. Agency for Toxic Substances and Disease Registry (ATDSR); CERCLA Priority List of Hazardous Substances, 2016, www. atsdr.cdc.gov/SPL/index.html, accessed in April 2016.

36. Amado-Filho, G. M.; Salgado, L. T.; Rebelo, M. F.; Rezende, C. E.; Karez, C. S.; Pfeiffer, W. C.; Braz. J. Biol. 2008, 68, 95.
37. Uysal, K.; Emre, Y.; Köse, E.; Microchem. J. 2008, 90, 67.

38. Biney, C. A.; Ameyibor, E.; Water Air Soil Pollut. 1992, 63, 273.

39. Silva, E.; Viana, Z. C. V.; Onofre, C. R. E.; Korn, M. G. A.; Santos, V. L. C. S.; Braz. J. Biol. 2016, 76, 194.

40. Agência Nacional de Vigilância Sanitária (ANVISA); Decreto No. 55871, de 26.03.1965, referente a Normas Reguladoras do Emprêgo de Aditivos paraAlimentos, 1965, http://portal.anvisa.gov. br/wps/wcm/connect/414d248047458a7d93f3d73fbc4c6735/ DECRETO+N\%C2\%BA+55.871,+DE+26+DE+MAR\% $\mathrm{C} 3 \% 87 \mathrm{O}+\mathrm{DE}+1965$.pdf?MOD=AJPERES, accessed in April 2016.

41. Commission Regulation (EC); No. 629/2008 of 2 July 2008 amending Regulation (EC) No. 1881/2006 Setting Maximum Levels for Certain Contaminants in Foodstuffs; Official Journal of the European Union 51, 6-9, 2008.

42. Nauen, C. E.; Compilation of Legal Limits for Hazardous Substances in Fish and Fishery Products; FAO Fisheries Circular, 764: Rome, 1983, p. 102.

Submitted: January 26, 2016

Published: April 15, 2016 